\title{
Study on conceptual model of regional pollution meteorological conditions in Guanzhong Urban Agglomeration
}

\author{
Cheng $\mathrm{Lu}^{I^{*}}$, Hu $\mathrm{Lin}^{I^{*}}$, Hu Shulan ${ }^{I^{*}}$, Wang $Q i^{I}$, Zhang Xia ${ }^{I}$ \\ ${ }^{1}$ Shaanxi Provincial Climate Center, 710014, Xi'an Shaanxi, China.
}

\begin{abstract}
This paper defined regional pollution day and regional heavy pollution day, calculated the atmospheric stability by Pasqual classification and the height of mixed layer by national standard method, established a conceptual model of meteorological conditions in Guanzhong Urban Agglomeration. The results show that: (1) The more possibility of the regional pollution and regional heavy pollution is, the lower the mixing layer height is. (2)The frequency of stability increased with degree of pollution, the frequency of regional heavy pollution stability reached nearly $60 \%$ as regional heavy pollution. (3)In heavily polluted area, the frequency of ground temperature inversion is nearly $90 \%$, the average cumulative temperature inversion thickness is $260 \mathrm{~m}$ at assurance rate of $80 \%$, and the maximum temperature inversion strength is $10.8^{\circ} \mathrm{C} / 100 \mathrm{~m}$.

(4) Regional pollution is easy to occur when the frequency of quiet wind is higher than $50 \%$. At the same time, it is easy to form wind convergence area in the hinterland of Guanzhong Area, which causes the accumulation of pollutants.
\end{abstract}

With the acceleration of global climate change and urbanization, particulate pollution is becoming more and more serious, and the problem of urban air pollution has attracted the attention of governments all over the world. Scholars at home and abroad have carried out extensive and in-depth research on air pollution ${ }^{[1-3]}$. In recent years, the city group of Guanzhong with Xi'an as the center has suffered from frequent and repeated environmental air pollution, which is in common with Beijing, Tianjin, Hebei and Zhengzhou. The ecological environment of Guanzhong urban agglomeration is fragile and showing a trend of deterioration. In view of the current situation of serious air pollution in the city group of Guanzhong, many scholars in Shaanxi have conducted in-depth research from different perspectives, Chen Jianwen and others ${ }^{[4-5]}$ respectively studied the variation law of the mixed layer thickness in Shaanxi Province and the haze weather and climate characteristics and variation law in Shaanxi Province over the years, Wang Shan and others ${ }^{[6-7]}$ analyzed the characteristics of air environment and the influence of meteorological conditions in the process of heavy pollution. However, there are few studies on the formation mechanism of air pollution and the transmission of pollutants in the Guanzhong area. In this paper, the relationship between different incoming pollutants and heavy pollution days in the Guanzhong urban agglomeration is analyzed by comprehensively using the meteorological observation data inside and outside the Guanzhong Urban Agglomeration, mesoscale numerical calculation data and pollution monitoring data, This paper discusses the causes and formation mechanism of heavy pollution days, establishes a three-dimensional meteorological field conceptual model, in order to solve the problem of "unclear mechanism" in the process of urban air pollution prevention and control, and provides research basis and technical support for precise air pollution control, assessment of air environment prevention and control measures, and improvement of environmental air quality.

\section{Data and Research Methods}

\subsection{Research Area}

Guanzhong Plain is adjacent to Qinling Mountains in the south, Weibei tableland in the north, Baoji Gorge in the West and Tongguan in the East, with a length of about 300 kilometers and an altitude of about 323-800 meters. Guanzhong urban agglomeration is the most densely populated area in Shaanxi Province, an important birthplace of Chinese civilization, the starting point of the ancient Silk Road, the only high-tech industrial development belt and spark technology industrial belt in the western region of China, and has a unique strategic position in the overall situation of national modernization construction and all-round opening pattern.

*Corresponding authors:

croad128@139.com(Cheng Lu), hllinbb@126.com(Hu Lin), hushulan1967@163.com(Hu Shulan) 


\subsection{Data and Methods}

\subsubsection{Data Source}

In this paper, we selected hourly temperature, wind direction, wind speed, cloud amount and other meteorological observation data from 2014 to 2018 from 12 representative meteorological stations (Fig. 1) with uniform distribution in Guanzhong Plain, the sounding data from Jinghe station for the same period and the daily and hourly $\mathrm{PM}_{2.5}$ and $\mathrm{PM}_{10}$ concentrations of the five cities.The meteorological data comes from the meteorological information center of Shaanxi Province, and the pollutant concentration data comes from the national environmental monitoring station. The data is accurate and reliable after preliminary quality control.

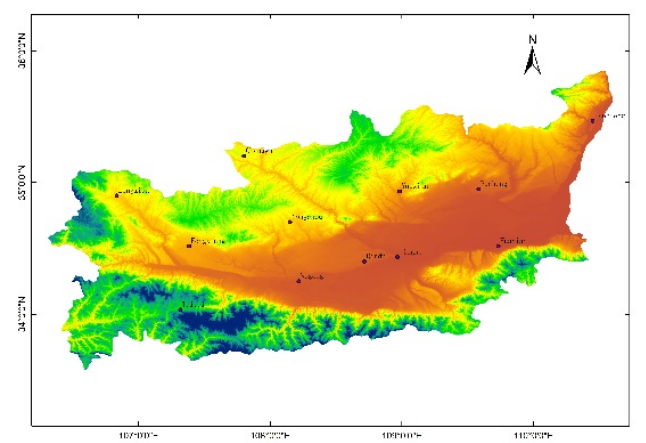

Fig. 1. Distribution of representative meteorological observation stations

\subsubsection{Methods}

In this paper, we definition of regional pollution day is that three or more cities in Guanzhong five cities have pollution, and the regional heavy pollution day is that three or more cities have moderate or more pollution. Selected the pollution index (AQI) of five cities in Guanzhong area since the PM2.5 monitoring in 20142018 , analyzed the distribution of five cities ( Table 1). There were 178 days of regional pollution days and 62 days of regional heavy pollution days in 2017 , the number of pollution days is the most in five years and the heavy pollution days is also belong to more years. Therefore, chosen 2017 as the representative year, and focuses on 2017 heavy pollution day.

Table 1. Pollution days in Guanzhong Area from 2014 to 2018

\begin{tabular}{|c|c|c|c|}
\hline Year & Regional & pollution days & Regional heavy pollution days \\
\hline 2014 & & 140 & 58 \\
\hline 2015 & & 84 & 30 \\
\hline 2016 & & 174 & 67 \\
\hline 2017 & & 178 & 62 \\
\hline 2018 & & 151 & 46 \\
\hline
\end{tabular}

The emission of pollutants is the main cause of air pollution, but the change of air pollution sources is generally small in a short period of time, so the meteorological conditions and duration of adverse diffusion are the trigger factors of air pollution ${ }^{[8]}$.
Meteorological conditions play a key role in the transport, diffusion, secondary transformation of air pollutants and even the occurrence of heavy pollution events [9], meteorological conditions that cause heavy air pollution events can also be regarded as a meteorological condition which is extremely harmful to the removal of pollutants.

This paper, selected the thickness of inversion layer, inversion intensity, mixed layer height, atmospheric stability level, wind direction and wind speed to characterize the atmospheric diffusion capacity. Among them, Pasquill classification method is used to classify atmospheric stability into six levels, strong unstable class A, unstable B class, weak unstable C class, neutral D class, stable E class and stable F.

\section{Basic Characteristics of Heavy Pollution Days}

According to the annual and monthly statistics of the distribution of pollution days in the Guanzhong region in 2017, it can be seen that: In the past five years, the average annual pollution day in Guanzhong region is $145.4 \mathrm{~d}$, The number of pollution days and heavy pollution days has a significant increase trend in the past five years (Table 2).The most most pollution days are in 2017 and the least in 2015.which occurs at most in 2017 and at least in 2015. According to the monthly variation of pollution days (Fig. 2 ), the distribution trend of pollution days at all levels is the same, which is more in autumn and winter than in summer, with the most in January and December and the least in September. Analyzed the main reasons for the daily change of pollution in Guanzhong area in recent years, on the one hand, the pollution emissions increase because of the heating in winter, it cause the ambient air quality to exceed the standard; on the other hand, with the climate warming, the number of cold air activities affecting the Guanzhong area in autumn and winter is significantly reduced, the frequency of quiet breeze is increased, atmospheric diffusion capacity decreased significantly, which may be one of the main reasons for the increase of pollution days in Guanzhong area in recent years. However, as the government continues to increase the intensity of regulatory measures, the regional pollution above medium level has been reduced.

Table 2. Annual trend of regional pollution days from 2014 to 2018 in Guanzhong Area

\begin{tabular}{ccc}
\hline Year & $\begin{array}{c}\text { Days of regional } \\
\text { pollution }\end{array}$ & $\begin{array}{c}\text { Days of heavy } \\
\text { pollution }\end{array}$ \\
\hline 2014 & 140 & 58 \\
\hline 2015 & 84 & 30 \\
\hline 2016 & 174 & 67 \\
\hline 2017 & 178 & 62 \\
\hline 2018 & 151 & 46 \\
\hline
\end{tabular}




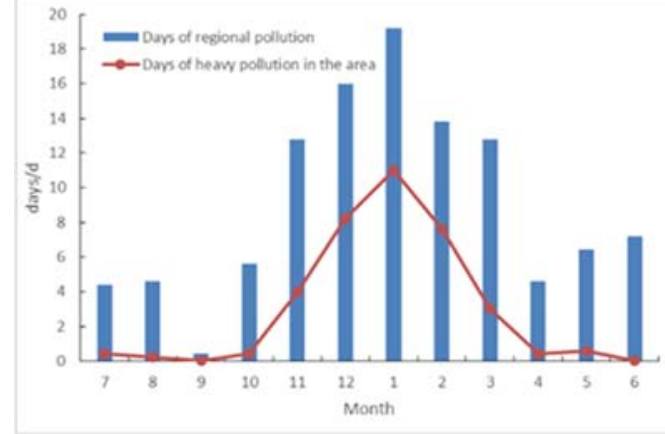

Fig. 2. Monthly variation of regional pollution days from 2014 to 2018 in Guanzhong Area

\section{Meteorological conditions and index analysis of heavy polluted weather}

A large number of studies show that ${ }^{[10]}$ :The meteorological conditions that lead to the occurrence of serious air pollution events can also be regarded as a kind of extremely unfavorable meteorological conditions for pollutant removal. This paper defined as autumn and winter from September to February according to the climate characteristics of Guanzhong, used the hourly meteorological data of 2017referring to relevant research conclusions, selected six meteorological factors, such as the height of the mixed layer, the atmospheric stability, the intensity of inversion, the thickness of inversion, the wind direction and the wind speed, to analyze the differences of the meteorological conditions and the atmospheric diffusion conditions of regional pollution in different intensity pollution situations in autumn and winter, extract relevant indicators and establish the air pollution Conceptual model of diffusion meteorological conditions.

\subsection{Mixed Layer Height}

Regional pollution in Guanzhong area mainly occurred in autumn and winter. The analysis shows that: when pollution occurs, the vertical diffusion ability of the atmosphere is weak, and the thickness of the mixed layer is small. Through analysis, it is found that when pollution occurs, the vertical diffusion ability of the atmosphere is poor and the thickness of the mixed layer is small, the daily average of regional pollution or regional heavy pollution is the highest proportion of mixed layer height between $50 \mathrm{~m}<\mathrm{h} \leqslant 300 \mathrm{~m}$. The maximum thickness of the average mixed layer non-regional pollution is $520 \mathrm{~m}$, he average thickness of pollution days is $500 \mathrm{~m}$, the thickness of heavy pollution days in the area is minimum only $380 \mathrm{~m}$. The proportion of the thickness of the lower mixing layer increases with the increase of regional pollution intensity (Table 3).

When regional pollution occurs, the proportion of the corresponding mixed layer height $\leqslant 50 \mathrm{~m}$ is $2.6 \%$, the largest proportion of $100 \mathrm{~m}<\mathrm{h} \leqslant 200 \mathrm{~m}$ is $21.1 \%$, followed by $200 \mathrm{~m}<\mathrm{h} \leqslant 300 \mathrm{~m} 19.3 \%$ The mixed layer height of $60 \%$ regional pollution is less than or equal to $350 \mathrm{~m}$;For regional heavy pollution, the proportion of mixed layer height $<50 \mathrm{~m}$ is $3 \%$, and the proportion of mixed layer height $<50 \mathrm{~m}<\mathrm{h}<100 \mathrm{~m}$ is $18.4 \%$ The proportion of mixed layer height between $100 \mathrm{~m}<\mathrm{h} \leqslant 300 \mathrm{~m}$ is $45.6 \%$ About $70 \%$ of the area is heavily polluted, and the height of the air mixing layer is less than or equal to $300 \mathrm{~m}$.

Table 3. Statistical mixing layer height index ( frequency \%) of regional air pollution in Guanzhong Area

\begin{tabular}{c|c|c|c}
\hline $\begin{array}{c}\text { Mixed Layer } \\
\text { Height (m) }\end{array}$ & $\begin{array}{c}\text { Non- } \\
\text { regional } \\
\text { pollution } \\
\text { frequency } \\
(\%)\end{array}$ & $\begin{array}{c}\text { Regional } \\
\text { pollution } \\
\text { frequency } \\
(\%)\end{array}$ & $\begin{array}{c}\text { Heavy } \\
\text { regional } \\
\text { pollution } \\
\text { frequency } \\
(\%)\end{array}$ \\
\hline$\leqslant 100$ & 12.3 & 17.4 & 21.4 \\
\hline $100<\mathrm{H} \leqslant 300$ & 41 & 40.4 & 45.7 \\
\hline $300<\mathrm{H} \leqslant 350$ & 4.4 & 4 & 4 \\
\hline $350<\mathrm{H} \leqslant 500$ & 6.9 & 5.3 & 5.2 \\
\hline $500<\mathrm{H} \leqslant 1000$ & 17.5 & 13.8 & 12 \\
\hline $1000<\mathrm{H} \leqslant$ & 11.9 & 12.1 & 9 \\
\hline 1500 & 6.1 & 6.9 & 2.9 \\
\hline$>1500$ & \multicolumn{2}{|c}{}
\end{tabular}

\subsection{Atmospheric Stability Level}

It can be seen from Fig. 3 that the frequency distribution characteristics of the three stability degrees are relatively consistent, there are all less unstable classes (A-C) and more stable classes (E-F). Among them, the stability of class A is less, even no stability of class A on the day of regional heavy pollution.It is worth noting that the frequency of stable classes is significantly different in various situations. The frequency of stable classes on the days non-regional pollution is about $40 \%$, while the frequency of stable classes on regional pollution and regional heavy pollution increases in turn. When regional pollution occurs, the frequency of stable classes is more than $50 \%$, and when regional heavy pollution occurs, the frequency of stable classes is nearly $60 \%$.
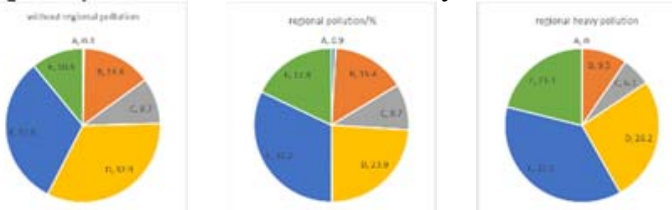

Fig. 3. Statistical atmospheric stability index (frequency \%) of regional air pollution in Guanzhong Area

\subsection{Inversion}

Based on the sounding data of Jinghe meteorological station from 2014 to 2018, calculated the intensity, thickness and cumulative thickness of ground inversion, analyzed the corresponding relationship between pollution and its degree is (Table 4). It can be seen that: When the area is heavily polluted, the occurrence frequency of the corresponding ground inversion is nearly $90 \%$, the maximum accumulated inversion thickness below $1500 \mathrm{~m}$ is $990 \mathrm{~m}$, the average cumulative inversion thickness of $80 \%$ assurance rate is $260 \mathrm{~m}$, the maximum 
inversion strength is $10.8{ }^{\circ} \mathrm{C} / 100 \mathrm{~m}$; For regional pollution and non-regional pollution, the frequency of ground inversion respectively is $72.6 \%$ and $58.1 \%$, the maximum inversion intensity respectively is $8.7^{\circ} \mathrm{C} / 100 \mathrm{~m}$ and $7.7^{\circ} \mathrm{C} / 100 \mathrm{~m}$.

Table 4. Inversion index statistics of regional air pollution in Guanzhong Area

\begin{tabular}{cccc}
\hline & $\begin{array}{c}\text { Daily average } \\
\text { cumulative } \\
\text { inversion } \\
\text { thickness (m) }\end{array}$ & $\begin{array}{c}\text { Average accumulated } \\
\text { inversion thickness } \\
\text { at } 80 \% \text { assurance } \\
\text { rate }\end{array}$ & $\begin{array}{c}\text { Ground } \\
\text { inversion } \\
\text { frequency (\%) }\end{array}$ \\
\hline $\begin{array}{c}\text { Regional } \\
\text { Heavy } \\
\text { Pollution }\end{array}$ & 345.4 & 260 & 89.3 \\
\hline $\begin{array}{c}\text { Regional } \\
\text { Pollution }\end{array}$ & 246.1 & 190 & 72.6 \\
\hline $\begin{array}{c}\text { Non- } \\
\text { regional } \\
\text { Pollution }\end{array}$ & 160.4 & 50 & 58.1 \\
\hline
\end{tabular}

The results show that: Inversion is an important factor ${ }^{[11-12]}$, it can further weaken the vertical diffusion ability of pollutants and further enhance the accumulation effect of pollutants. The results consistent with the relevant research conclusions. And radiosonde data of Jinghe Station show that the higher the occurrence frequency of ground inversion, the thicker the accumulated inversion, the stronger the inversion intensity, and the stronger the pollution intensity in the corresponding area.

\subsection{Wind Direction and Speed}

It can be seen from Fig. 4: With the increase of pollution intensity, the daily frequency of different intensity pollution increases in turn while the wind speed $<=1.5 \mathrm{~m}$ / s. When wind speed $>1.5 \mathrm{~m} / \mathrm{s}$, the pollution intensity of the section decreased in turn with the increase of the pollution intensity. Among them, the frequency of regional heavy pollution is $6.9 \%$ when it is calm wind, and that of small wind $(0 \mathrm{~m} / \mathrm{s}<$ wind speed $<=1.5 \mathrm{~m} / \mathrm{s})$ is nearly $55 \%$, which is significantly higher than that of no regional pollution. Correspondingly, when there is no regional pollution, the frequency of high wind speed is significantly higher than that of regional pollution and regional heavy pollution. Furthermore, it can be concluded that: when the frequency of quiet and small wind is higher than $50 \%$, regional pollution is easy to occur, and when the frequency of quiet and small wind is higher than 55\%, regional heavy pollution is easy to occur. It is further verified that the smaller the wind speed is, the weaker the diffusion ability of the atmosphere is, and the accumulation of pollutants near the formation is easy to cause environmental air pollution.
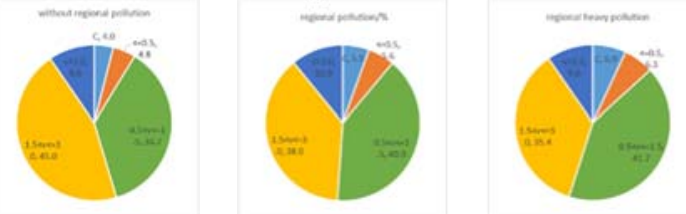

Fig. 4. Statistical wind speed frequency(\%) of regional air pollution in Guanzhong
Wind direction is another main factor affecting the concentration distribution of pollutants. The change of dominant wind direction can reflect the evolution of weather system. It can be seen from Fig. 5 that the distribution characteristics of the dominant wind direction of the 12 index stations in the central area of Guanzhong are significant when the area is heavily polluted. The west of the central area of Guanzhong is dominated by the northwest wind. The east of the central area of Guanzhong and the hinterland of Guanzhong are mostly dominated by the northeast wind.

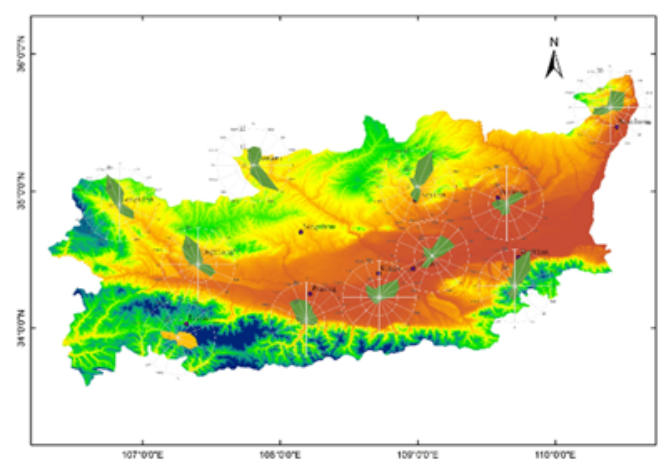

Fig. 5. Wind rose of each station with regional air pollution in Guanzhong

In addition, the blocking of the Qinling Mountains and the northern tableland in the south, it is easy to form a wind convergence area in the central area of Guanzhong, which causes the accumulation of pollutants and the process of regional heavy pollution. Comparing the regional pollution of different intensities, we can find that the frequency of dominantwind direction decreases, convergence weakens and convergence frequency decreases with the decrease of pollution intensity.

\section{Conceptual Model of Regional Pollution Meteorological Conditions}

This paper discussed the change of meteorological conditions and its effect in the occurrence and development of heavy air pollution events in Guanzhong urban, established the independent meteorological condition discrimination index of atmospheric heavy pollution, summarized the conceptual model of different degrees of pollution days conditions in Guanzhong Region (as shown in Fig. 6).

\section{Conclusion and Discussion}

This paper used the environmental pollution monitoring data and meteorological data of the same period in Guanzhong region, defined the weather process of regional heavy pollution and regional pollution, analyzed the main characteristics of meteorological elements in the process of regional pollution with different intensities, established the conceptual model of weather and meteorological conditions of different degrees of pollution in Guanzhong area, the conclusion is as follows: 
(1) From 2014 to 2018, the average annual pollution days in Guanzhong region is $145.4 \mathrm{~d}$, the number of pollution days and heavy pollution days has an obvious increasing trend, and the pollution days at all levels are more in autumn and winter than in summer.

(2) The regional pollution in Guanzhong area mainly occurs in autumn and winter. The more possibility of the regional pollution and regional heavy pollution is, the lower the mixing layer height is.In case of regional heavy pollution, the height of air mixing layer corresponding to $70 \%$ of regional heavy pollution is less than or equal to $300 \mathrm{~m}$.

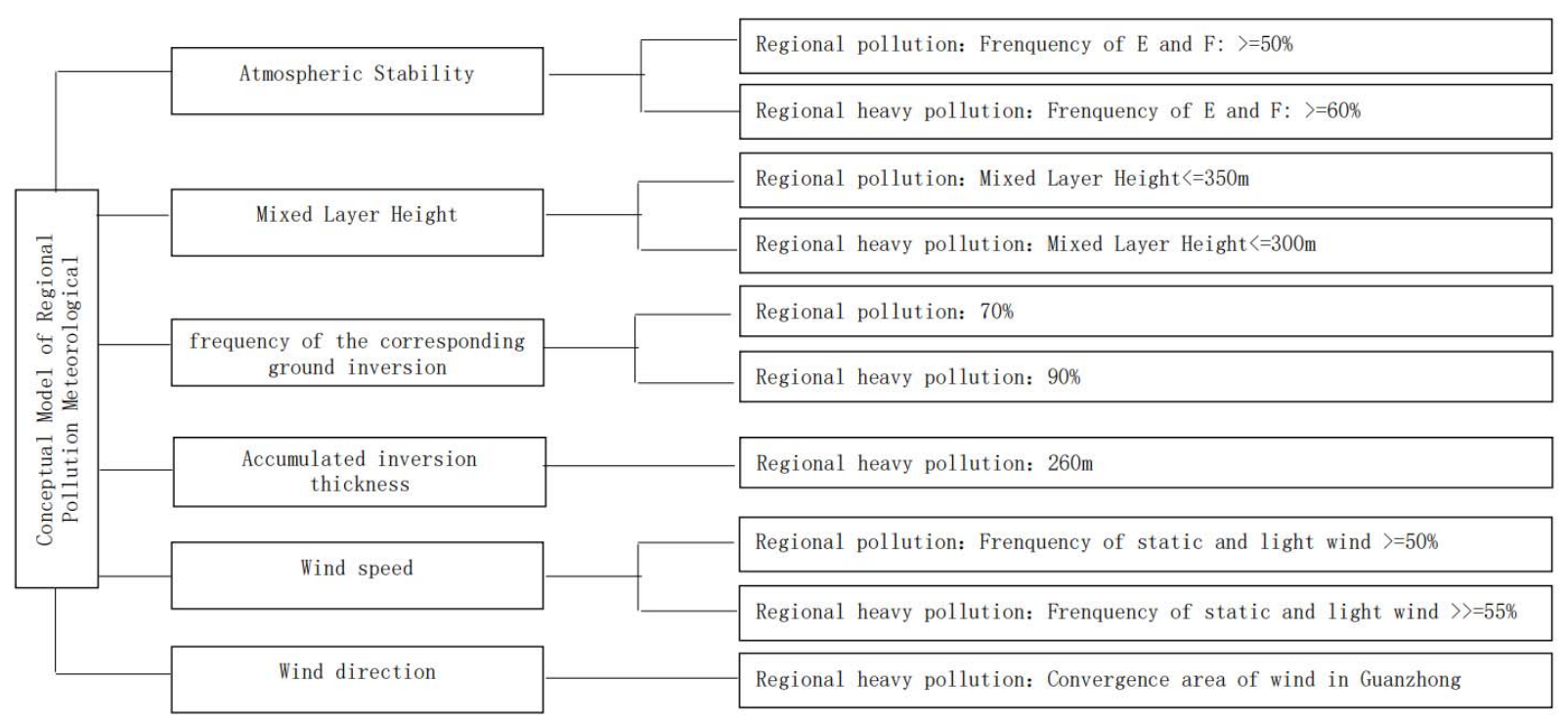

Fig. 6. Conceptual model of regional air pollution meteorological conditions in Guanzhong

(3) The stability of Guanzhong region in autumn and winter is the most stable (E-F), there is significant difference in frequency of regional stable pollution intensity, the frequency of stable at non-regional pollution is about $40 \%$, the frequency of regional pollution and regional heavy pollution stability increased in turn, the frequency of stable at regional heavy pollution is as high as $60 \%$.

(4) The regional pollution intensity in Guanzhong increased with the increase of inversion index. When the area is heavily polluted, The frequency of ground inversion is nearly $90 \%$, the maximum accumulated inversion thickness at low altitude below $1500 \mathrm{~m}$ is $990 \mathrm{~m}$, $80 \%$ assurance rate of average cumulative inversion thickness is $260 \mathrm{~m}$, and the maximum inversion strength is $10.8^{\circ} \mathrm{C} / 100 \mathrm{~m}$.

(5)In Guanzhong area, the daily frequency of different intensity pollution in the quiet and small wind

section increased in turn with the increase of pollution intensity. When the frequency of quiet wind is higher than $50 \%$, regional pollution is easy to occur. At the same time, it is easy to form wind convergence area in the hinterland of Guanzhong, which causes the accumulation of pollutants.

\section{Acknowledgement}

This work was supported by a climate change project (CCSF201938) from the China Meteorological Administration. This thesis was completed based on the support and encouragement of many people. The authors are thankful for the guidance of Professor Li Zhan Bin from the Xi'an University of
Technology and Professor Fang Jian Gang from the Shaanxi Climate Center. I would like to thank all the authors for their helpful conversations.

\section{Reference}

1. F.Wang,D.S.Chen,S.Y.Cheng,J.B. Identification of regional atmospheric PM10 transport pathways using HYSPLIT,MM5-CMAQ and synoptic pressure pattern analysis[J].Environmental Modelling and Software.2010(8):927-934

2. Liu Jun,An XingQin,Zhu Tong,Evaluation of PM2.5 decrease in Beijing after emission restrictions in the Beijing-Tianjin-Hebei and surrounding regions $[\mathrm{J}]$. China Environmental Science, 2014,34(11):27262733.

3. Jiang Y R,Zhu K Y,et al.Numerical simulation on the air pollution potential in the severe air pollution episodes in Beijing-Tianjin-Hebei region [ $\mathrm{J}]$.Acta Scientiae Circumstantiae, 2015,35(9):2681-2692.

4. Hu Lin,Zhang Xia,Su Jing,Characteristics analysis and c Climatic Forming Reasons of haze weather in Shaanxi province[J].Arid Land Geography, 2019,42(4):707-714.

5. Chen Jianwen,Hu Lin,Wang Juanmin. Distribution Charateristics of the Mixed Layer Height in Shaanxi Province [J]. Research of Soil and Water Conservation, 2014, 21 (5): 322-326.

6. Wang Shan,Liao Tingting,Wang Lili,Atmospheric characteristics of a serious haze episode in $\mathrm{Xi}^{\prime}$ an and 
the influence of meteorological conditions, [J].Acta Scientiae Circumstantiae, 2015,35(11):3452-3462.

7. Huang Shaini,Yuan Yuan,Jing Yu. Characteristics of a Severe Haze Pollution Process in Winter and Meteorological Cause in Guanzhong of Shaanxi [J].Journal of Arid Meteorology,2016,34(6):10371046.

8. Zhang H D, Zhang B H, Lü M Y, et.al. Development and application of stable weather index of Beijing in environmental meteorology [J]. Meteorological Monthly, 2017, 43 (8): 998-1004 (in Chinese)

9. Mei M, Zhu R, Sun C Y. Study on meteorological conditions for heavy air pollution and its climatic characteristics in " $2+26$ " cities around BeijingTianjin-Hebei region in autumn and winter [J]. Climate Change Research, 2019, 15 (3): 270-281
10. Du Wupeng, Fang Xiaoyi, Liu Yonghong.Indexes and Zoning Research of Wind Environmental Capacity for Metropolis - A Case of Beijing,Climate Change Research,2017, 13 (6):526-533.

11. Mei Mei,Zhu Rong. Variation Trend and Genesis Analysis of Atmospheric Diffusion Conditions in Key Areas of Pollution Control [J]. Environmental Impact Assessment,2017,39(5):1-6.

12. LIANG Xiao-yu, SHAN Chun-yan,Characteristics and formation mechanism of a heavy winter air pollution event in Tangshan [J]. China Environmental Science,2019, 39(5):1804-1812. 